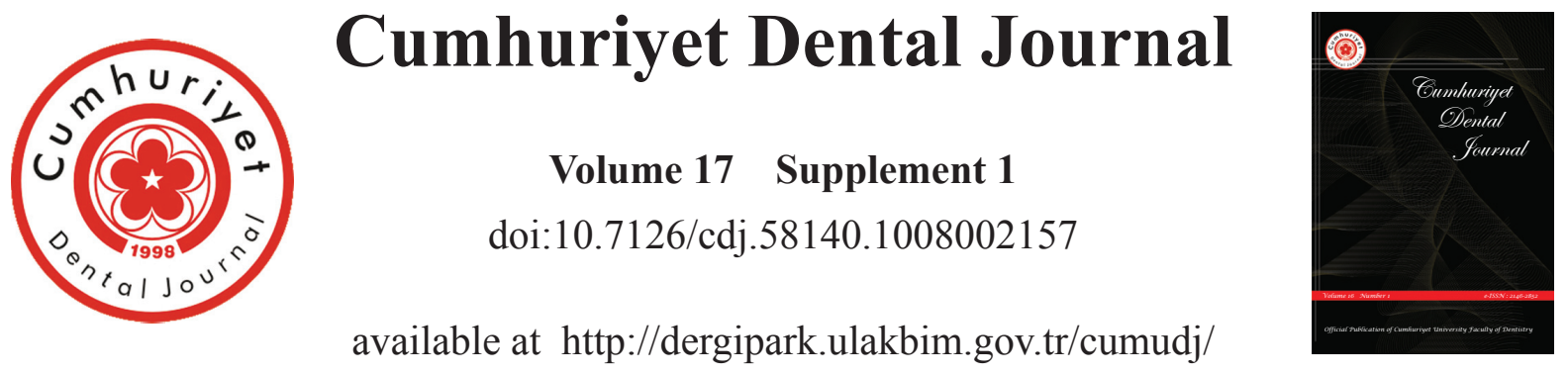

CASE REPORT

\title{
Maxillary sinusitis as a complication of an extruded gutta-percha: a case report
}

\author{
Yener Oguz, DDS, $\mathrm{PhD},{ }^{a}$ Sidika Sinem Soydan, $\mathrm{DDS}, \mathrm{Ph} \mathrm{D}^{b}$ \\ ${ }^{a}$ Department of Oral and Maxillofacial Surgery, Baskent University, Faculty of Dentistry, Ankara, Turkey \\ ${ }^{b}$ Department of Oral and Maxillofacial Surgery, Baskent University, Faculty of Dentistry, Ankara, Turkey
}

\section{A R T I C L E I N F O}

\section{Article history:}

Received 09 May 2013

Accepted 07 October 2013

\section{Keywords:}

Maxillary sinusitis

Extruded gutta-percha

Endodontic treatment

\begin{abstract}
A B S T R A C T
The purpose of this article is to report the maxillary sinusitis caused by the extruded root canal material into the sinus. A 35-year-old woman was referred to our clinic with facial pain, accompanied by sinusitis, swelling, tenderness to palpation and sensitivity to chewing in the right maxillary region. The radiograph showed extruded gutta-percha (GP) from the apex of the right maxillary second premolar into the maxillary sinus. A well-circumscribed radiopaque mass in relation to the root and extending into the sinus owing to chronic inflammation was easily observed. Surgical management was performed under local anaesthesia. The inflammatory tissue around the apex of the tooth was removed by the help of a curette. The root end and the extruded GP were resected with a fissure bur, and the sinus was irrigated with saline solution. An initial panoramic radiograph will reveal the proximity of the apices to the maxillary sinus. Using an electronic apex detector, applying a good apical stop, or moderate condensation will help to avoid overfilling or overextending of the endodontic material. Besides, periapical radiographs can also be taken to avoid any mistakes. However, contaminated root canal materials can easily induce maxillar sinusitis or aspergillosis.
\end{abstract}

\section{INTRODUCTION}

Maxillary sinusitis of odontogenic origin have been reported with the perforation of schneiderian membrane, which occurs due to dentoalveolar or periodontal surgery, dental trauma, periapical abscesses and extrusion of the endodontic materials. ${ }^{1-4}$ In most cases, roots of the maxillary teeth are in a close relationship with the floor of the maxillar sinus or apexes protrude into the sinüs. ${ }^{5}$ Overinstrumentation and extrusion of the endodontic obturation materials during root canal treatment of the maxillary molar teeth may also cause sinusitis or aspergillosis due to the zinc oxide based cements. ${ }^{6,7}$ Aspergillus has a dense opacity foreign body reaction associated with the maxillary sinus infection; however, not all extrusions cause aspergillosis in the maxillary sinus. ${ }^{8}$ The purpose of this article

Corresponding author at: Yener OGUZ, Assistant Professor, 11. sok. No: 26 Department of Oral and Maxillofacial Surgery, Faculty of Dentistry, Baskent University, 06490, Bahcelievler, Ankara, Turkey, Tel: +90 312 2151336. Fax: +90 312 2152962. E-mail: yenero80@yahoo.com 
is to report the maxillary sinusitis caused by the extruded root canal material into the sinus.

\section{CASE REPORT}

A 35-year-old woman was referred to our clinic (Baskent University, Faculty of Dentistry, Oral and Maxillofacial Surgery Department, Ankara, Turkey) with facial pain, accompanied by sinusitis, swelling, tenderness to palpation and sensitivity to chewing in the right maxillary region. The patient revealed having undergone an endodontic treatment on the right maxillary second premolar nearly a year ago. Clinical examination revealed no probing depth along the root or mobility; but, a positive response to percussion on the related tooth. A panoramic radiograph was taken for further examination. The radiograph showed the root to be in close proximity to the sinus. Besides, the root canal treatment had been finished, and a five millimeters guttapercha (GP) was extruded from the apex into the maxillary sinus. Moreover, a wellcircumscribed radiopaque mass in relation to the root and extending into the sinus owing to chronic inflammation was easily observed (Figure 1). After the diagnosis and



Figure 1. Extruded gutta-percha from the apex and a well-circumscribed radiopaque mass in the sinus. consultation with an endodontic specialist, it was decided to perform apical surgery with access via the maxillary sinus.

Surgical management was performed under local anaesthesia of $4 \%$ articaine hydrochloride (HCL) with 1:100.000 adrenaline. Lateral wall of the maxillary sinus was seen after elevating the buccal flap from mesial of the first premolar to distal of the second molar. Besides, the lateral aspect of the sinus was exposed by using a round bur under irrigation (Figure 2). The inflammatory tissue around the apex of the tooth was removed by the help of a curette (Figure 3). The root end and the extruded GP were resected with a fissure bur, and the sinus was irrigated with saline solution. The flap was sutured with a 3-0 silk suture. The patient was prescribed to take Amoxicillin (Augmentin ${ }^{\circledR}$ GlaxoSmith Kline, Istanbul, Turkey) $1000 \mathrm{mg}$ BID tb/12h for a week, Flurbiprofen (Majezik ${ }^{\circledR}$ Sanovel, Istanbul, Turkey) $100 \mathrm{mg} \mathrm{tb} / 12 \mathrm{~h}$ for a week, and $0.12 \%$ Chlorhexidine-gluconate solution (Kloroben ${ }^{\circledR}$ Drogsan, Ankara, Turkey) three times a day for a week. Sutures were removed on the seventh day. The healing was uneventful. The patient did not show any post-operative symptoms for one year, and the radiograph showed normal anatomic formation (Figure 4).

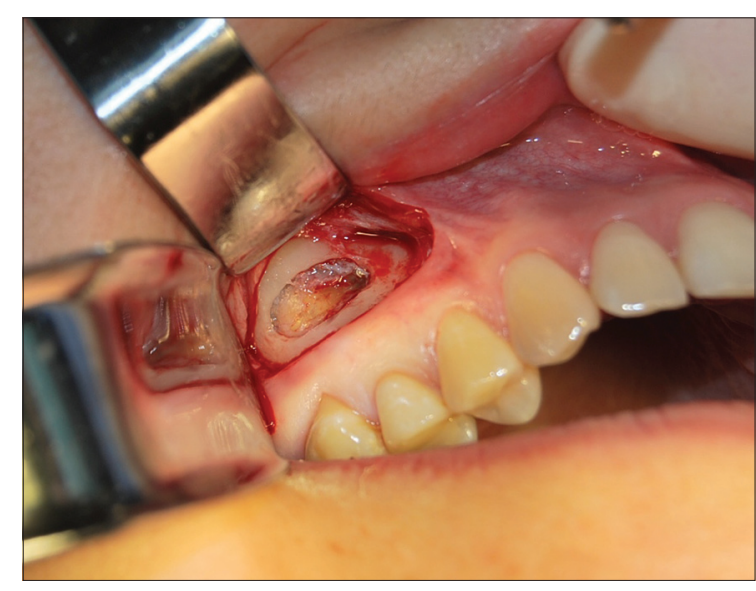

Figure 2. Lateral aspect of the sinus was exposed by using a round bur under irrigation. 


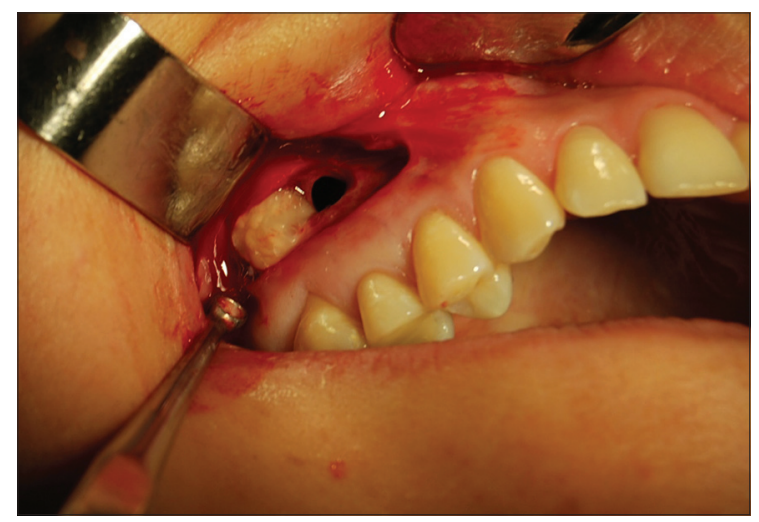

Figure 3. Inflammatory tissue around the apex of the tooth was removed.

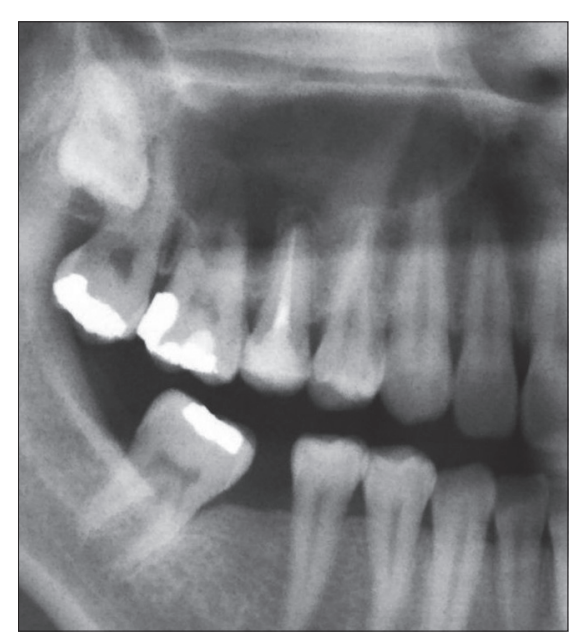

Figure 4. Panoramic radiograph taken one year after the surgery shows normal anatomic formation.

The histopathologic examination revealed that the inflammatory cell infiltration was included in the connective tissue, but showed no evidence of aspergillosis.

\section{DISCUSSION}

Several complications arise due to inadequate or incorrect treatment of the root canals. Some of the complications related to the overextension and/or overfilling of the maxillary molar or premolarare aspergillosis and sinusitis of odontogenic origin, orbital abscess, orbital pain, headache, etc. ${ }^{9}$ Owing to the anatomic locations, maxillary sinuses could be easily invaded by microorganisms from the oral cavity. About one-tenth of the cases related to maxillary sinusitis originated from odontogenic sources. ${ }^{10} \mathrm{~A}$ higher incidence of anaerobic bacteria found in acute maxillary sinusitis caused by odontogenic infections. ${ }^{3}$ In $40 \%$ cases, the roots of first and second maxillary molars were close to the floor of maxillary sinus. ${ }^{11}$ Due to this close relationship between the root of maxillary premolar-molar teeth and the maxillary sinus, careful radiographic diagnosis must be done during the endodontic treatment of these teeth. ${ }^{6}$ However, an accidental perforation of the schneiderian membrane during the root canal treatment or an intrusion of the obturation materials into the maxillary sinus may also cause sinusitis or aspergillosis. ${ }^{12}$

In this case report, there was no alveolar bone between the apex of the roots and the sinus membrane; consequently the roots of the maxillary teeth were in the maxillar sinus. Besides, the poorly fitting master cone was extruded five millimeters into the sinus without even being realised. This inexcusable mistake of the clinician caused an infection in the maxillary sinus after one year of operation.

Based on the fact that zinc is considered as a growth factor of aspergillosis and some root canal materials include zinc oxide, the authors' first diagnosis after recognising the circumscribed radiopaque mass in relation to the root and extending into the sinus was aspergillosis. Beck-Mannagetta et al. $^{12}$ concluded that maxillary sinus aspergillosis was mostly caused by zinc oxide and formaldehyde including rootfilling materials. Moreover, Most cases concerning aspergillosis of the maxillary sinus were related to the overextended root canal sealer in the maxillary teeth. ${ }^{13}$

In contrast to the pre-diagnosis by the authors, the histopathologic examination revealed that the inflammatory cell 
infiltration was included in the connective tissue, without any evidence of aspergillosis.

An initial panoramic radiograph will reveal the proximity of the apices to the maxillary sinus. Using an electronic apex detector, applying a good apical stop, or moderate condensation will help to avoid overfilling or overextending of the endodontic material. ${ }^{9}$ Besides, periapical radiographs can also be taken to avoid any mistakes. However, contaminated root canal materials can easily induce maxillar sinusitis or aspergillosis.

\section{REFERENCES}

1. Nair UP, Nair MK. Maxillary sinusitis of odontogenic origin: Conebeam volumetric computerized tomography-aided diagnosis. Oral Surg Oral Med Oral Pathol Oral Radiol Endod. 2010;110:53-57.

2. Kretzschmar DP, Kretzschmar JL. Rhinosinusitis: Review from a dental perspective. Oral Surg Oral Med Oral Pathol Oral Radiol Endod. 2003;96:128-135.

3. Brook I. Sinusitis of odontogenic origin. Otolaryngol Head and Neck Surg. 2006;135:349-355.

4. Yanık S, Ege B, Keskinrüzgar A, Aras $\mathrm{MH}$, Ay S. Actinomyces infection related with maxillary sinus: Case report. Cumhuriyet Dent J. 2013;16:133-137.

5. García $B$, Peñarrocha $M$, Peñarrocha MA, Von Arx T. Apical surgery of a maxillary molar creating a maxillary sinus window using ultrasonics: A clinical case. Int Endod J. 2010;43:1054-1061.
6. Yamaguchi $\mathrm{K}$, Matsunaga $\mathrm{T}$, Hayashi Y. Gross extrusion of endodontic obturation materials into the maxillary sinus: A case report. Oral Surg Oral Med Oral Pathol Oral Radiol Endod. 2007;104:131-134.

7. Yaltirik $M$, Koçak Berberoglu $H$, Koray M, Dulger O, Yildirim S, Aydil BA. Orbital pain and headache secondary to overfilling of a root canal. J Endod. 2003;29:771-772.

8. Khongkhunthian $P$, Reichart PA. Aspergillosis of the maxillary sinus as a complication of overfilling root canal material into the sinus: Report of two cases. J Endod. 2001;27:476-478.

9. González-Martín M, TorresLagares D, Gutiérrez-Pérez JL, Segura-Egea JJ. Inferior alveolar nerve paresthesia after overfilling of endodonticsealerintothemandibular canal. J Endod.2010;36:1419-1421.

10. Mehra P, Murad H. Maxillary sinus disease of odontogenic origin. Otolaryngol Clin North Am. 2004;37:347-364.

11. Wallace JA. Transantral endodontic surgery. Oral Surg Oral Med Oral Pathol Oral Radiol Endod. 1996;82:80-83.

12. Beck-Mannagetta J, Necek D, Grasserbauer M. Solitary aspergillosis of maxillary sinus, a complication of dental treatment. Lancet. 1983;26:1260.

13. Legent $F$, Billet J, Beauvillain C, Bonnet J, Miegeville M. The role of dentalcanal fillingsin the development of Aspergillus sinusitis. A report of 85 cases. Arch Otorhinolaryngol. 1989;246:318-320.

How to cite this article: Yener Oguz, Sidika Sinem Soydan. Maxillary sinusitis as a complication of an extruded gutta-percha: a case report. Cumhuriyet Dent J 2014;17(Supp 1):36-39. 